\title{
Camptothecin and cisplatin upregulate ABCG2 and MRP2 expression by activating the ATM/NF-кB pathway in lung cancer cells
}

\author{
SHI ZHONG KE ${ }^{1}$, XIAO YAN NI ${ }^{1}$, YUE HUA ZHANG ${ }^{1}$, YI NAN WANG ${ }^{1}$, BIN WU ${ }^{2}$ and FENG GUANG GAO ${ }^{1}$ \\ ${ }^{1}$ Department of Immunology, Basic Medicine Science, Medical College, Xiamen University, Xiamen 361005; \\ ${ }^{2}$ Department of Pharmacology, Affiliated Renji Hospital of Shanghai Jiao Tong University, Shanghai 200030, P.R. China
}

Received November 17, 2012; Accepted January 4, 2013

DOI: $10.3892 /$ ijo.2013.1805

\begin{abstract}
Multidrug resistance (MDR) formation is an important problem in lung cancer chemotherapy. Our study showed that both camptothecin and cisplatin could not only induce ATM and NF- $\kappa$ B activation but also upregulate expression of the MDR-related genes ABCG2, MRP2 in NCI-H446 cells. Moreover, camptothecin and cisplatin-induced ABCG2 and MRP2 upregulation could be impaired by ATM and NF- $\mathrm{B}$ inhibitors, indicating a relationship between ATM, NF- $\kappa$ B activation and MDR formation in lung cancer chemotherapy. Our study indicates that ATM may serve as a potential molecular target for MDR formation in lung cancer chemotherapy.
\end{abstract}

\section{Introduction}

Small cell lung cancer (SCLC), which accounts for $\sim 15 \%$ of all lung cancer cases, is the most aggressive metastatic form of lung cancer and does not respond well to surgery or radiotherapy (1). Although up to $90 \%$ of small cell lung cancer (SCLC) initially responds to chemotherapy, patients with SCLC often relapse with multidrug resistant formation (MDR), leading to 5-year survival $<5 \%(2,3)$ indicating that MDR is a major obstacle for successful small cell lung cancer chemotherapy. ATP-binding cassette transporter proteins such as ATP-binding cassette (ABC) transporters P-glycoprotein (P-gp, MDR1), multidrug resistance-associated protein (MRP) and breast cancer resistance protein (BCRP/ABCG2) $(4,5)$, transporting a wide variety of chemical compounds

Correspondence to: Professor Feng Guang Gao, Department of Immunology, Basic Medicine Science, Medical College, Xiamen University, Siming Nan Road, Xiamen 361005, P.R. China

E-mail: gfengguang@xmu.edu.cn

Dr Bin Wu, Department of Pharmacology, Affiliated Renji Hospital of Shanghai Jiao Tong University, Shanghai 200030, P.R. China

E-mail:wbsjtu@gmail.com

Key words: ataxia telangietisa mutanted, NF- $x \mathrm{~B}, \mathrm{ABCG} 2, \mathrm{MRP} 2$, lung cancer in ATP-dependent manner, have been found to contribute to MDR formation in a variety of tumors arising from gastric, renal, endometrium, melanoma and soft tissue (6-12). However, the role of ABCG2 and MRP2 in lung cancer associated MDR formation is still uncertain and this is important for dealing with lung cancer associated multidrug resistance.

Various cellular pathways might be simultaneously involved in the clinical drug resistance of cancer patients (13-22). Ataxia telangiectasia mutanted (ATM), a nuclear serine-threonine kinase involving in DNA double strand break (DSB) repair, was reported to upregulate MDR associated genes expression and contribute to multidrug resistance (14-16). NF- $\kappa \mathrm{B}$, which is involved in regulating apoptosis, inflammatory response, cell survival and immune response, was also reported to play roles in tumor growth, invasion and metastasis (18-22). Although the phosphorylation of NEMO Ser $^{85}$ by ATM was shown in HEK293 cells (23), the role of ATM-NF- $\kappa$ B pathway in lung cancer associated MDR formation is still uncertain and needs further exploration.

In the present study, human small cell lung cancer NCI-H446 cells were used as lung cancer model and the roles of ATM/ $\mathrm{NF}-\kappa \mathrm{B}$ activation induced by chemotherapeutic drugs in MDR formation were explored. The results showed that: firstly, the expressions of ABCG2, MRP2 and Bcl-2 were upregulated in response to camptothecin and cisplatin treatment; secondly, ATM and NF- $\kappa$ B pathways were activated by camptothecin or cisplatin treatment; moreover, $\mathrm{NF}-\kappa \mathrm{B}$ activation was dependent on ATM phosphorylation in camptothecin or cisplatin treatment conditions; most importantly, both ABCG2 and MRP2 upregulation induced by camptothecin could be impaired by $\mathrm{NF}-\kappa \mathrm{B}$ and ATM inhibitors. These findings indicated that chemotherapeutic drugs such as camptothecin and cisplatin could upregulate ABCG2 and MRP2 expression by activating $\mathrm{ATM} / \mathrm{NF}-\kappa \mathrm{B}$ pathway in small cell lung cancer chemotherapy, providing ATM as potential target molecular for overcoming lung cancer chemotherapy-associated multidrug resistance.

\section{Materials and methods}

Reagents. Reagents were purchased from the following companies: Rhodamine 123 (rho123; Molecular Probes, Eugene, OR, USA) was the dye used to detect early stage of cell apoptosis. 
Calcein-AM (Molecular Probes) is a cell permeate dye that can be used to determine cell viability. Camptothecin (CPT) and cisplatin (DDP) were purchased from Calbiochem (San Diego, CA, USA). Anti-phospho-IкB $\alpha$, anti-p65, anti-phospho-p65, anti-ATM, anti-phospho-ATM, anti-ABCG2, anti-MRP2 and anti-Bcl-2 were from Cell Signaling Technology (Beverly, MA, USA). Anti-histone $\mathrm{H} 3$, anti- $\beta$-actin and anti-tubulin were from Santa Cruz Biothenology (Santa Cruz, CA, USA).

Cell line and treatment condition. Small cell lung cancer (NCI-H446) cells (American Type Culture Collection, HTB-171, Bethesda, MD, USA) were grown in RPMI-1640 mediacontaining penicillin/streptomycin(Gibco, Gaithersburg, MD) and $10 \%$ fetal bovine serum (Hyclone, Logan, UT) at $37^{\circ} \mathrm{C}$ in $5 \% \mathrm{CO}_{2}$. NCI-H446 cells were passaged every 2 days. Cells were synchronized by serum starvation (in RPMI-1640 without serum) for $\geq 12 \mathrm{~h}$ before treated with dose-escalated camptothecin or cisplatin for $18 \mathrm{~h}$.

Cell apoptosis assay. Cell apoptosis assay was determined by flow cytometry according to the method described previously (24). Briefly, NCI-H446 cells were treated with camptothecin or cisplatin for $18 \mathrm{~h}$ at indicated final concentration. Then, cells were removed by trypsinization, rinsed with PBS and re-suspended in binding buffer containing Annexin V-FITC and propidium iodide (PI) for $20 \mathrm{~min}$ at room temperature. The samples were analyzed on FACSCalibur and data were analyzed with CellQuest software.

Measurement of mitochondrial membrane potential by flow cytometry. Mitochondrial membrane was monitored using the fluorescent dye Rhodamine 123, which detected the early stage of cell apoptosis (25). Briefly, NCI-H446 cells were treated with camptothecin or cisplatin for $18 \mathrm{~h}$ at indicated final concentration. Then, cells were rinsed with PBS and Rhodamine 123 was added at a final concentration of $1 \mu \mathrm{g} / \mathrm{ml}$. After 15 min co-incubation at $37^{\circ} \mathrm{C}$, the cells were collected, washed twice with PBS and then analyzed by flow cytometry.

Calcein-AM has been used as an excellent tool for the studies of cell membrane integrity and is a true end-point assay for cell viability. Calcein-AM (final concentration of $0.5 \mu \mathrm{M}$ ) was added to cells after camptothecin or cisplatin treatment as described above. After 15-min co-incubation at $37^{\circ} \mathrm{C}$, the cells were collected, washed twice and analyzed by flow cytometry.

Confocal immunofluorescence assay. The effect of ATM phosphorylation and p65 nuclear translocation were investigated by immunofluorescence assay as described previously (26). Briefly, NCI-H446 cells were serum-starved for $\geq 12 \mathrm{~h}$ followed by $0.5 \mu \mathrm{g} / \mathrm{ml}$ camptothecin stimulation for indicated periods. Then, cells were fixed and permeabilized in $100 \%$ methanol for $15 \mathrm{~min}$, washed with PBS and blocked with $10 \%$ non-fat milk in PBS for $3 \mathrm{~h}$. Primary antibodies (phospho-p65 or phospho-ATM) were incubated in a humid chamber overnight at $4^{\circ} \mathrm{C}$. Finally, FITC-conjugated secondary antibodies were incubated for $1 \mathrm{~h}$ at $37^{\circ} \mathrm{C}$ and DAPI counterstaining was performed to visualize cell nuclei. The cells were observed and images were recorded by a confocal fluorescence microscope at the wavelength of $488 \mathrm{~nm}$. ATM phosphorylation inhibitor
CGK $(20 \mu \mathrm{M})$ was pre-treated for $1 \mathrm{~h}$ before camptothecin treatment to observe the effect of ATM activation on p65 phosphorylation and translocation. Cells were washed three times in each step to remove non-binding substance.

Cytoplasmic and nuclear extracts isolation. Cytoplasmic and nuclear extracts from whole cell extracts were prepared as described previously (27). Briefly, NCI-H446 cells were treated with camptothecin or cisplatin for $18 \mathrm{~h}$ at indicated final concentration. Then, cells were suspended in ice-cold CER buffer (cytoplasmic extraction reagent), vortexed for $10 \mathrm{~min}$ and ice-cold CER was added. The cytosolic fraction (supernatant) was separated by centrifugation $(16000 \mathrm{x} \mathrm{g}$, $5 \mathrm{~min}, 4^{\circ} \mathrm{C}$ ) and the nuclear protein was separated by incubating insoluble fraction with ice-cold NER (nuclear extraction reagent) for $40 \mathrm{~min}$ and centrifuged at $16000 \mathrm{x} \mathrm{g}$ for $10 \mathrm{~min}, 4^{\circ} \mathrm{C}$. Protein concentration was estimated using the Bio-Rad protein assay reagent and an equal amount of proteins per sample of nuclear extract was further analyzed by Western blotting.

Western blot analysis. Proteins were obtained in lysis buffer as previously described (28). To investigate the effects of camptothecin or cisplatin on MDR-related genes expression, NCI-H446 cells were treated with camptothecin or cisplatin at indicated concentration. Protein lysates were electrophoresed on 8-10\% SDS-PAGE gels, then transferred to PVDF membranes and blotted with primary antibodies. Followed by appropriate peroxidase-conjugated secondary antibodies and detected by chemiluminescence ECL. $\beta$-actin, tubulin or histone were used as loading control.

Statistical analysis. Each experiment was repeated at least 3 times and confirmed that similar data were obtained. All data were expressed as mean and standard error means. Statistical significance was tested using one-way ANOVA with post Newman-Keuls test. Statistical differences were considered to be significant at $\mathrm{p}<0.05$.

\section{Results}

Both cisplatin and camptothecin independently change mitochondrial membrane potential and induce cell apoptosis. To investigate the pro-apoptosis effect of camptothecin and cisplatin, NCI-H446 cells were exposed to different concentrations of camptothecin or cisplatin for $18 \mathrm{~h}$ and analyzed by flow cytometry. The results showed that: both camptothecin and cisplatin could effectively induce apoptosis in a concentration-dependent manner, as both of $0.5 \mu \mathrm{g} / \mathrm{ml}$ camptothecin and $1 \mu \mathrm{g} / \mathrm{ml}$ cisplatin could induce $\sim 10 \%$ apoptosis (Fig. 1A-C). Analysis of early stage cell apoptosis found that camptothecin or cisplatin efficiently changed the mitochondrial membrane potential, which was demonstrated by enhanced release of Rhodamine 123 from the mitochondria and mean of fluorescence index increase in intracellular fluorescence (Fig. 1D and E). Cell viability determination of Calcein-AM analysis showed that $0.1 \mu \mathrm{g} / \mathrm{ml}$ camptothecin or $0.5 \mu \mathrm{g} / \mathrm{ml}$ cisplatin treatment affected cell viabilities of NCI-H446 cells (Fig. $1 \mathrm{~F}$ and G). These data indicated that $>1 \mu \mathrm{g} / \mathrm{ml}$ camptothecin or cisplatin efficiently induced cell apoptosis, while lower 
A

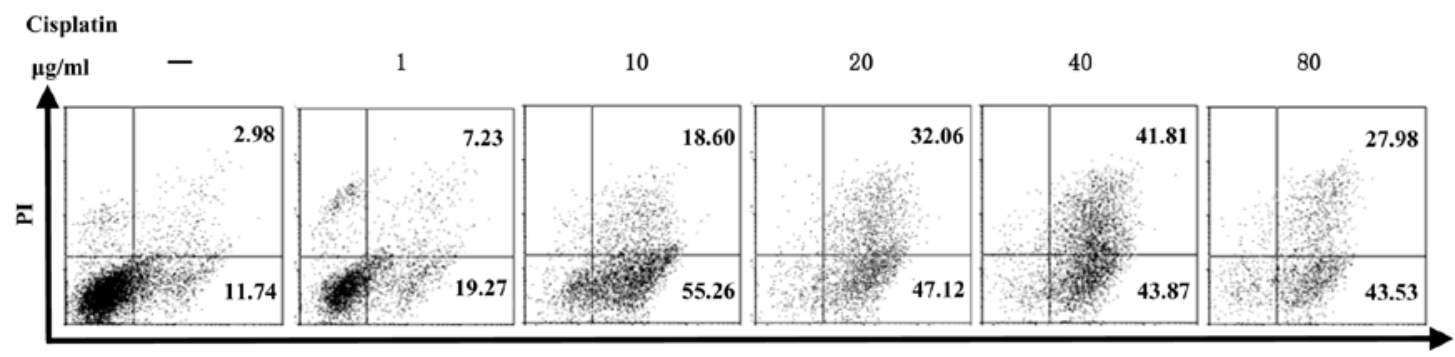

B

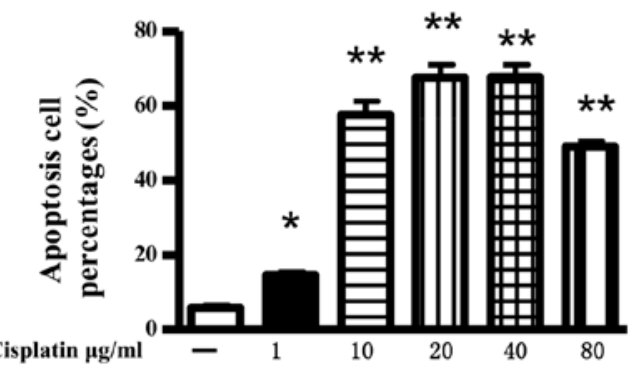

D

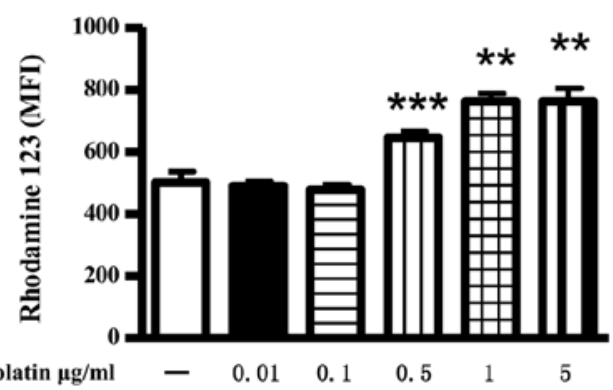

F

Cisplatin $\mu \mathrm{g} / \mathrm{ml}$

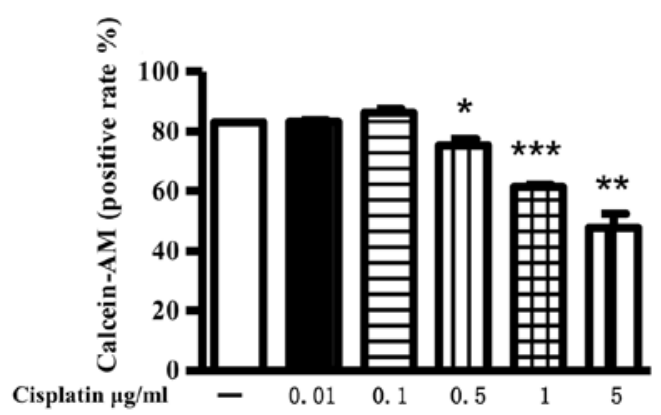

nexin V

C

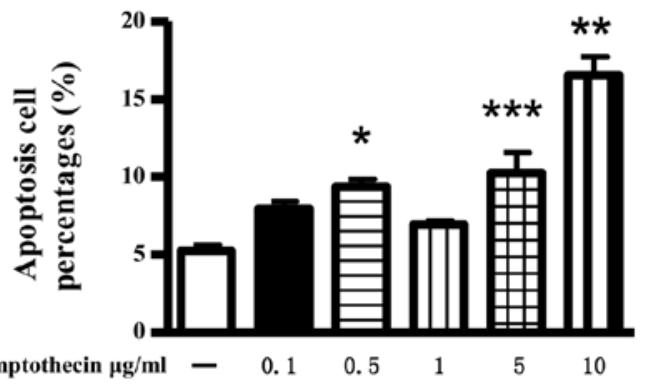

E

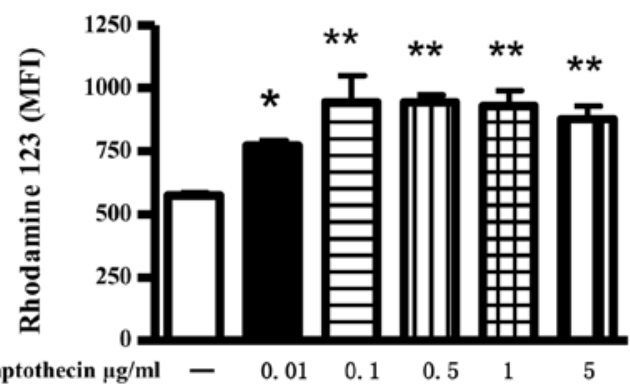

G

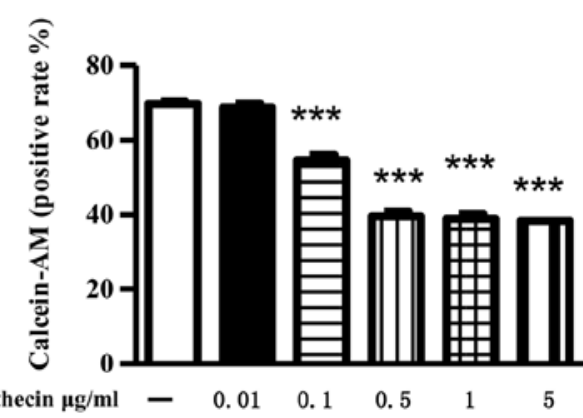

Figure 1. Cisplatin and camptothecin, respectively, changes mitochondrial membrane potential and induces cell apoptosis. NCI-H446 cells were treated with cisplatin (A, C, D and F) or camptothecin (C, E and G) for $18 \mathrm{~h}$ in indicated final concentration. Cell apoptosis (A-E), and cell viability (F and G) were determined by flow cytometry using Annexin-V/PI (A-C), Rhodamine 123 (D and E) and Calcein-AM (F and G) respectively. Lower concentration of cisplatin $(0.5 \mu \mathrm{g} / \mathrm{ml})(\mathrm{D})$ or camptothecin $(0.1 \mu \mathrm{g} / \mathrm{ml})(\mathrm{E})$ induced early stage of cell apoptosis and affected the cell viability (F and G). Representative flow cytometry analysis out of three is shown. Data are given as the mean SEM, $\mathrm{n}=3$. ${ }^{*} \mathrm{p}<0.05 ;{ }^{* *} \mathrm{p}<0.01$; ${ }^{* * *} \mathrm{p}<0.001$; compared with control, one-way ANOVA with post Newman-Keuls test.

concentration camptothecin or cisplatin induced early stage cell apoptosis and had no effect on cell viability.

The expression of ABCG2, MRP2 and Bcl-2 was upregulated by camptothecin or cisplatin stimulation in NCI-H446 cells. To investigate the effects of camptothecin and cisplatin on expression of ABCG2, MRP2 and Bcl-2, NCI-H446 cells were treated with camptothecin or cisplatin and the expressions of ABCG2, MRP2 and Bcl-2 was determined by Western blotting. The results showed that cisplatin stimulation obviously increased ABCG2 and MRP2 expressions in a concentra- tion- (0.1-5 $\mu \mathrm{g} / \mathrm{ml})$ (Fig. 2A) and time-dependent manner (3-24 h) (Fig. 2C), which reach the maximum at $1 \mu \mathrm{g} / \mathrm{ml}$ and $24 \mathrm{~h}$ respectively. Similar to cisplatin, camptothecin upregulated ABCG2, and MRP2 expression in a concentration- (0.01-1 $\mu \mathrm{g} /$ ml) (Fig. 2B) and time-dependent manner (1-24 h) (Fig. 2D). Interestingly, not only ABCG2 and MRP2 but also Bcl-2 was upregulated by cisplatin or camptothecin stimulation from 3 to $24 \mathrm{~h}$ (Fig. 2C and D). Collectively, these data indicated that camptothecin or cisplatin treatment induced the expression of multidrug resistance protein and anti-apoptosis protein, contributing to MDR formation in NCI-H446 cells. 
A

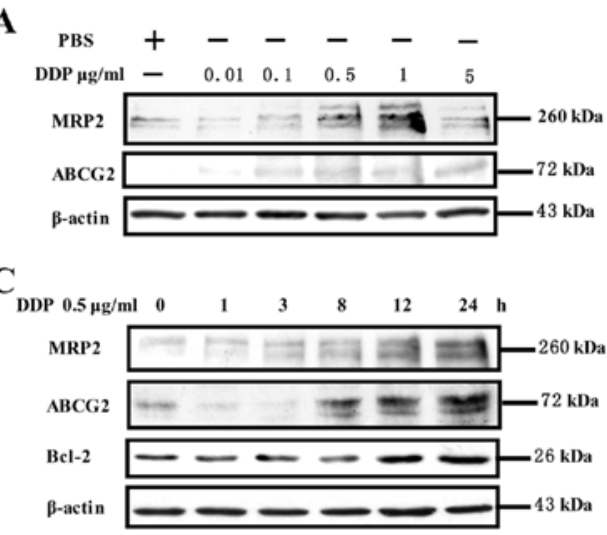

B

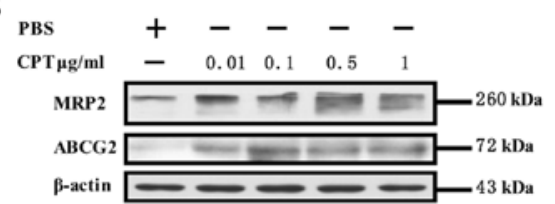

D

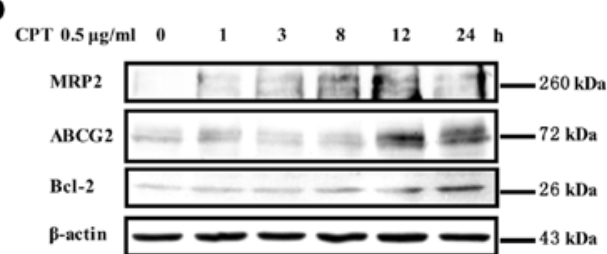

Figure 2. Treatment with cisplatin or camptothecin upregulates ABCG2, MRP2 and Bcl-2 expression in NCI-H446 cells. NCI-H446 cells were treated with cisplatin (A and B) or camptothecin (C and D) in indicated concentration for $18 \mathrm{~h}$ for indicated periods. Then, the cellular protein was extracted and ABCG2, MRP2, Bcl-2 expression was determined by Western blotting. $\beta$-actin was used as loading control. Data shown are representative of three independent experiments ( $\mathrm{n}=3)$. DDP, cisplatin; CPT, camptothecin.

A

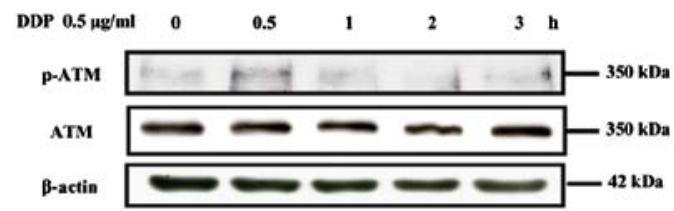

B

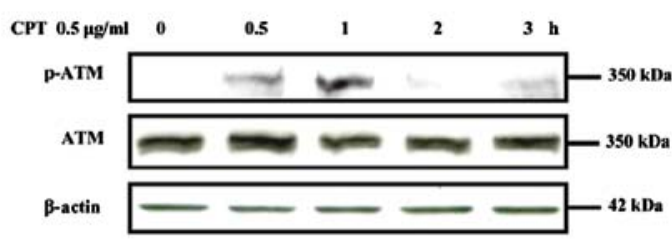

C
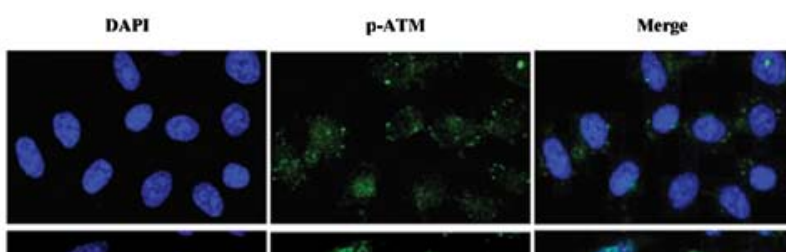

CPT 0.5 h
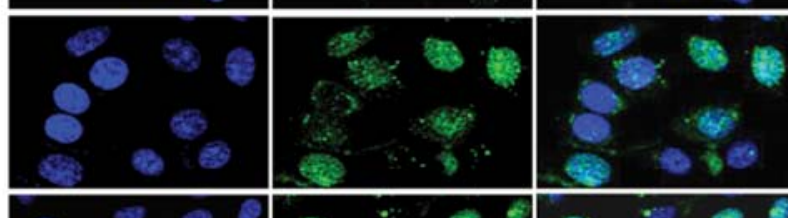

CPT 1 h
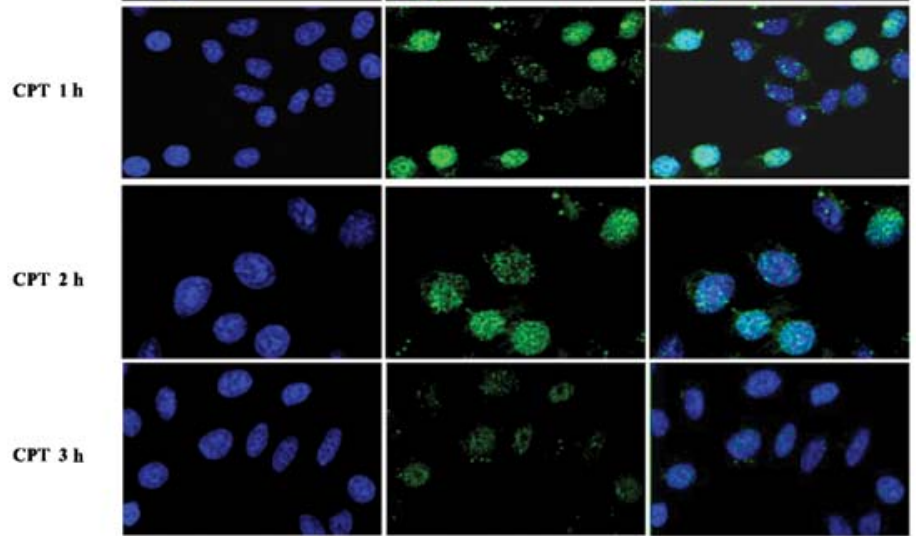

Figure 3. Treatment with cisplatin or camptothecin induces ATM phosphorylation in NCI-H446 cells. NCI-H446 cells were treated with cisplatin (A) or camptothecin (B and C) at a final concertration of $0.5 \mu \mathrm{g} / \mathrm{ml}$ for indicated periods. ATM phosphorylation was determined by Western blotting and confocal immunofluorescence assay, respectively, with anti-phospho-ATM antibodies. Both cisplatin (A) and camptothecin (B and C) treatments enhanced ATM phosphorylation. Data shown are representative of three independent experiments $(n=3)$. $\beta$-actin was used as loading control. DDP, cisplatin; CPT, camptothecin. 
$\mathbf{A}$

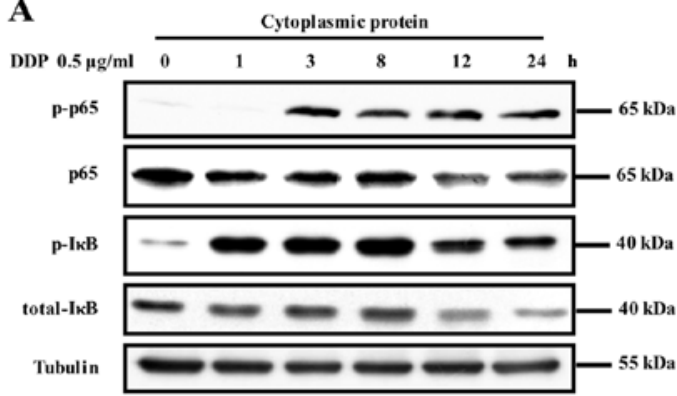

C

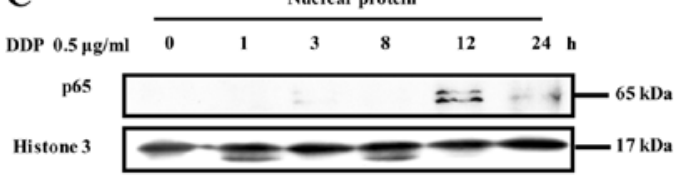

B

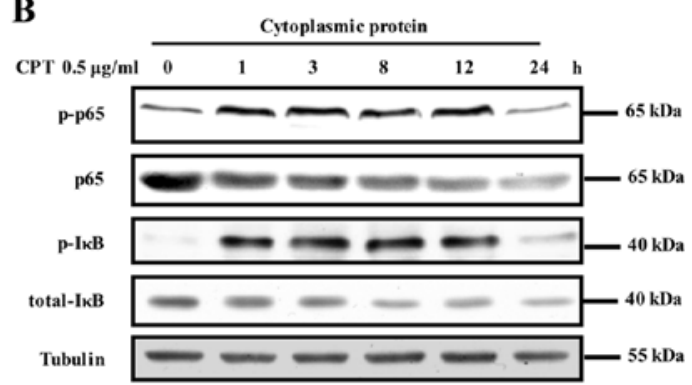

D

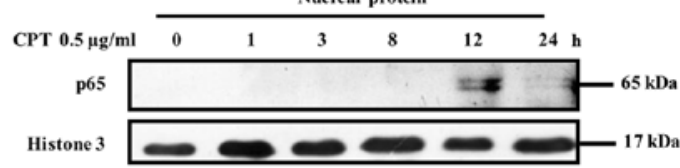

Figure 4. Camptothecin or cisplatin activates the NF-кB pathway and enhances p65 translocation in NCI-H446 cells. Serum-starved NCI-H446 cells were firstly treated with $0.5 \mu \mathrm{g} / \mathrm{ml}$ of cisplatin or camptothecin for indicated time. Then, cytoplasmic and nuclear extracts were prepared, electrophoresis was performed and electrotransferred to PVDF membrane. The activation of NF- $\kappa B$ pathway induced by cisplatin (A) or camptothecin (B) and p65 translocation enhanced by cisplatin (C) or camptothecin (D) were determined by Western blotting. (A) Cisplatin treatment promoted I $\mathrm{B} \alpha$ degradation and phosphorylation

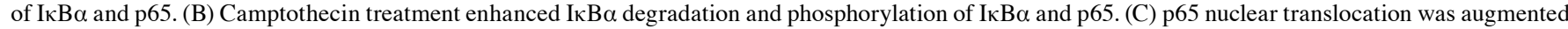
by cisplatin treatment. (D) p65 nuclear translocation was enhanced by camptothecin treatment. Data shown are representative of three independent experiments ( $n=3$ ). Tubulin (A and B) or histone H3 (C and D) was used as loading control.

Camptothecin or cisplatin activates ATM in NCI-H446 cells. ATM, a serine/threonine protein kinase, could be activated by ionizing radiation or other agents such as etoposide which induces DNA double strand breaks (29). To determine the effect of camptothecin and cisplatin on ATM activation in lung cancer cells, NCI-H446 cells were treated with camptothecin or cisplatin and ATM phosphorylation was observed by Western blotting and laser confocal microscope respectively. The results showed that $0.5 \mu \mathrm{g} / \mathrm{ml}$ camptothecin or cisplatin treatments obviously increased ATM phosphorylation in NCI-H446 cells in time-dependent manner which reach the maximum at $1 \mathrm{~h}$ after the exposure to camptothecin or cisplatin (Fig. 3A and B). The immunofluorescence observation found that camptothecin increased the phosphorylation of ATM from 0.5 to $3 \mathrm{~h}$, which reach the maximum at $1 \mathrm{~h}$ after camptothecin stimulation (Fig. 3C).

Camptothecin or cisplatin can activate the $N F-\kappa B$ pathway in NCI-H446 cells. Phosphorylation and degradation of $\mathrm{I} \kappa \mathrm{B} \alpha$, the natural blocker of NF- $\kappa \mathrm{B}$ and a direct downstream protein activated by phosphorylated IKK, is well known as an important prerequisite for the activation of $\mathrm{NF}-\kappa \mathrm{B}(16,26)$. To investigate the effects of camptothecin and cisplatin on $\mathrm{NF}-\kappa \mathrm{B}$ pathway activation, NCI-H446 cells were treated with camptothecin or cisplatin and phosphorylation of $\mathrm{I} \kappa \mathrm{B} \alpha, \mathrm{p} 65$ and p65 translocation were determinated by Western blotting. The results showed that both $\mathrm{I} \kappa \mathrm{B} \alpha$ and p 65 phosphorylation in cytoplasm was increased at $3 \mathrm{~h}$ and remained elevated at $8 \mathrm{~h}$ after camptothecin or cisplatin treatment. In contrast, total I $\mathrm{B} \alpha$ and total p65 in cytoplasm decreased accordingly in a time-dependent manner (Fig. 4A and B). Consistent with phosphorylation of $\mathrm{I} \kappa \mathrm{B} \alpha$ and p65 in cytoplasm, the translocation of p65 from cytoplasm to neuclei was observed at $3 \mathrm{~h}$ and reached the maximum at $12 \mathrm{~h}$, which remained elevated at
$24 \mathrm{~h}$ after camptothecin or cisplatin treatment (Fig. 4C and D), indicating that camptothecin or cisplatin stimulation induced $\mathrm{NF}-\kappa \mathrm{B}$ pathway activation in NCI-H446 cells.

ATM phosphorylation is involved in camptothecin or cisplatin-induced $\mathrm{NF}-\kappa \mathrm{B}$ activation in NCI-H446 cells. Two independent studies have reported an essential role of ATM in DSB-induced NF- $\kappa$ B activation $(14,30)$. To explore the role of ATM phosphorylation in camptothecin and cisplatin-induced $\mathrm{NF}-\kappa \mathrm{B}$ activation, ATM phosphorylation inhibitor CGK was used prior to camptothecin or cisplatin treatment and $N F-\kappa B$ activation, the translocation was determined by Western blotting and confocal microscrope observation, respectively. The results showed that camptothecin stimulation effectively induced both p65 and I $\mathrm{B} \alpha$ phosphorylation from 3 to $12 \mathrm{~h}$ (Fig. 5A) and enhanced p65 translocation from cytoplasm to nucleus (Fig. 5B), CGK $(20 \mu \mathrm{M})$ pre-treatment decreased IкB $\alpha$ and p65 phosphorylation (Fig. 5A) and blocked p65 translocation (Fig. 5B). As BAY, an NF- $\kappa$ B activation inhibitor, could effectively inhibit p65 phosphorylation (Fig. 5A) and translocation (Fig. 5B), the reduction of $\mathrm{NF}-\kappa \mathrm{B}$ activation derived by the usage of CGK indicated that camptothecin induced $\mathrm{NF}-\kappa \mathrm{B}$ activation was ATM phosphorylation dependent in NCI-H446 cells.

Camptothecin upregulates the expressions of ABCG2, MRP2 and $B c l-2$ by activating the ATM/NF- $\mathrm{B}$ pathway. To explore the role of $\mathrm{ATM} / \mathrm{NF}-\kappa \mathrm{B}$ activation in camptothecin-induced upregulation of ABCG2, MRP2 and Bcl-2 in NCI-H446 cells, ATM phosphorylation inhibitor $\mathrm{CGK}$ and $\mathrm{NF}-\kappa \mathrm{B}$ inhibitor BAY were used prior to camptothecin stimulation and the expressions of ABCG2, MRP2 and Bcl-2 was determined by Western blotting. The results showed that camptothecin stimulation obviously enhanced MRP2, Bcl-2 (Fig. 6A) and 


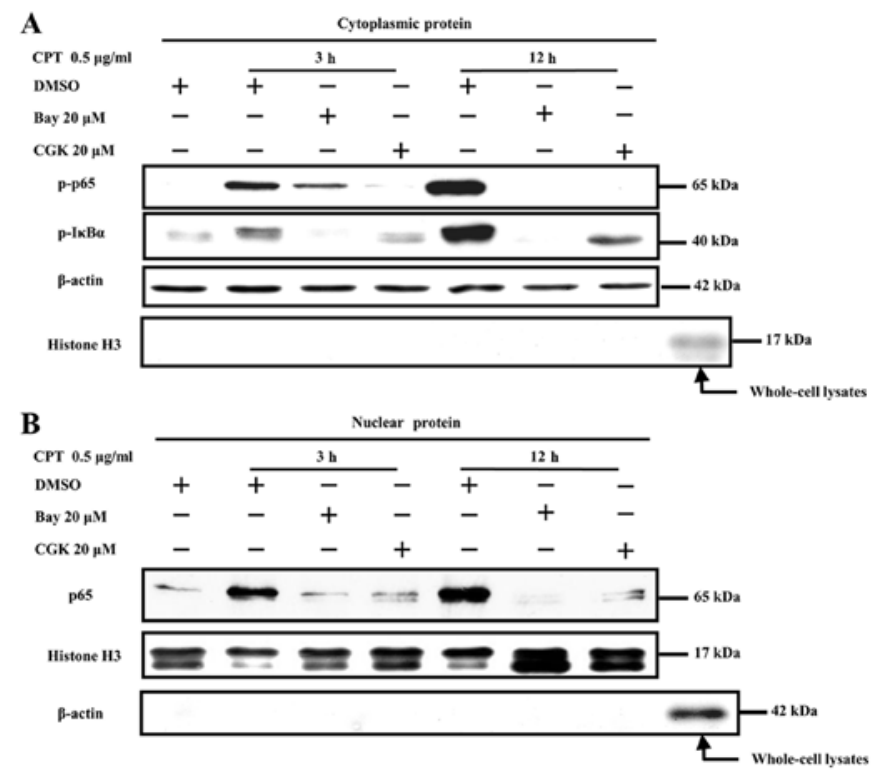

Figure 5. ATM phosphorylation was necessary for camptothecin-induced $\mathrm{NF}-\kappa \mathrm{B}$ pathway activation in NCI-H446 cells. NCI-H446 cells were pretreated with ATM inhibitor CGK $(20 \mu \mathrm{M})$, NF- $\mathrm{BB}$ inhibitor BAY $(20 \mu \mathrm{M})$ $60 \mathrm{~min}$ prior to camptothecin $(0.5 \mu \mathrm{g} / \mathrm{ml})$ stimulation. The phosphorylation of I $\mathrm{B} \alpha, \mathrm{p} 65$ and the translocation of $\mathrm{p} 65$ were determined by Western blotting (A and B). ATM phosphorylation was necessary for camptothecin-induced phosphorylation of IкB $\alpha$ and p65 (A) and p65 translocation (B). $\beta$-actin was used as loading control. Data shown are representative of three independent experiments $(\mathrm{n}=3)$.
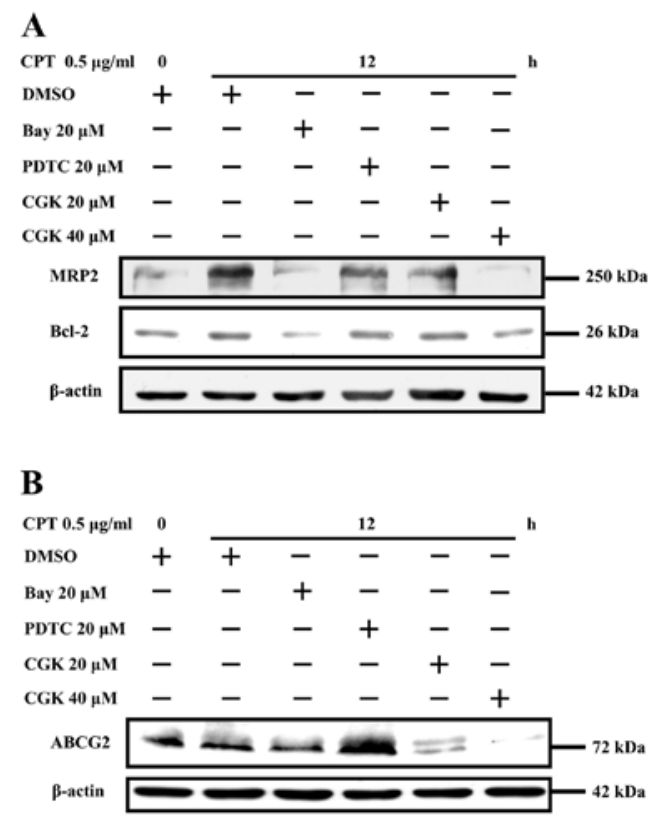

Figure 6. Camptothecin upregulated $\mathrm{ABCG} 2, \mathrm{MRP} 2$ and $\mathrm{Bcl}-2$ by activating ATM/NF- $\mathrm{BB}$ pathway in NCI-H446 cells. NCI-H446 cells were pre-treated with BAY, PDTC, CGK at indicated concentration $1 \mathrm{~h}$ prior to camptothecin $(0.5 \mu \mathrm{g} / \mathrm{ml}) 12-\mathrm{h}$ stimulation. Protein was extracted and the expression of ABCG2, MRP2 and Bcl-2, respectively, was determined by Western blotting. Data shown are representative of three independent experiments $(n=3)$. $\beta$-actin was used as loading control.

ABCG2 (Fig. 6B) expressions, the usage of ATM phosphorylation inhibitor $\mathrm{CGK}$ and effectively eliminated the upregulation effect of camptothecin on MRP2, Bcl-2 (Fig. 6A) and ABCG2
(Fig. 6B) expression in a CGK concentration-dependent manner. NF- $\kappa \mathrm{B}$ activation inhibitor BAY was also found to block MRP2, Bcl-2 and ABCG2 upregulation induced by camptothecin. However, the inhibitory effect of PDTC on MRP2, Bcl-2 and ABCG2 upregulation was not clear, which might be due to PDTC that did not inhibit camptothecininduced NF- $\kappa \mathrm{B}$ activation, as Togashi et al showed that PDTC did not inhibit tumor necrosis factor- $\alpha$-induced NF- $\kappa$ B activation in astrocytes (31). As CGK $(20 \mu \mathrm{M})$ and BAY $(20 \mu \mathrm{M})$ were capable of sufficiently inhibiting NF- $\kappa \mathrm{B}$ activation, the inhibition effect of CGK and BAY on ABCG2, MRP2, Bcl-2 expressions indicated that camptothecin upregulated ABCG2, MRP2 and Bcl-2 expression, respectively, by activating ATM/ $\mathrm{NF}-\kappa \mathrm{B}$ pathway in NCI-H446 cells.

\section{Discussion}

Although doxorubicin has been reported to induce MRP1 expression by activating the c-jun kinase pathway in human small cell lung cancer cell lines (1), a definitive conclusion with regard to the impact of drug resistance factors can not be derived due to the heterogeneity of the present study. Thus, MDR associated genes and mechanism need further exploration for dealing with chemotherapeutic multidrug resistance. In the present study, ABCG2 and MRP2 were used as representative multidrug resistance proteins and the roles of ATM-NF- $\kappa$ B activation in lung cancer-associated MDR formation were investigated in camptothecin or cisplatin treatment conditions. Our results showed that: ATM and NF- $\kappa$ B activation, resulting in cell survival, play an essential role in MDR development in camptothecin or cisplatin treated NCI-H446 cells; importantly, camptothecin or cisplatin was able to upregulate ABCG2, MRP2 expression by activating the ATM-NF- $\kappa$ B pathway, which was demonstrated by ATM and NF- $\kappa$ B inhibitors abrogating camptothecin-increased ABCG2 and MRP2 expression, indicating that ATM inhibitor might be useful for overcoming multidrug resistance in lung cancer chemotherapy.

Mitochondrial membrane potential is a key indicator of cellular viability, which reflects the pumping of hydrogen ions across the inner membrane during the process of electron transport and oxidative phosphorylation. In the present study, mitochondrial membrane was monitored by Rhodamine 123 and Calcein-AM flow cytometry. As Rhodamine 123 preferentially partition into active mitochondria based on depolarization of mitochondrial membrane potential when early stage cell apoptosis results in the release of Rhodamine 123 from the mitochondria and an increase in intracellular fluorescence (25). Calcein-AM is a widely used green fluorescent cell marker which is membrane permeant and can be introduced into cells via incubation. Once inside the cells, calcein-AM, a non-fluorescent molecule itself, is hydrolyzed by endogenous esterase into the highly negatively charged green fluorescent calcein and retained in the cytoplasm in live cells (32).

Function-deficient mutations of ATM has been reported in ataxia telangiectasia, which account for autosomal recessive disorder of cerebella ataxia, oculocutaneous telangiectasia, immunodeficiency, radiation sensitivity, growth retardation, premature aging and cancer predisposition (33). 
ATM was also implicated recently in metabolic pathways seemingly unrelated to DNA damage (34). However, as DNA damage sensor (14), ATM is a nuclear serine-threonine kinase involved in DNA double strand break (DSB) repair and plays an important role in chemotherapeutic drug induced MDR formation. Although the present study showed that ATM could be activated by camptothecin and cisplatin and ATM phosphorylation was crucial for the upregulation of ABCG2 and MRP2, the mutation of ATM induced by chemotherapeutic drug and the relationship of ATM mutation and MDR formation could be very important for lung cancer chemotherapy and needs further clarification.

Korita et al (35) reported that MRP2 expression determines the efficacy of cisplatin-based chemotherapy in patients with hepatocellular carcinoma. The MRP1 upregulation in tumors after chemotherapy attributed to selection of pre-existing MDR cells was also reported (12,36-38). Several studies have been performed to investigate potential correlation between ABCG2 expression and clinical outcomes. Given the specific tissue localizations, the role of ABCG2 in healthy tissue may be to protect an organism or tissue from potentially harmful toxins. Here we showed that significant increases of ABCG2, MRP2 and Bcl-2 were observed within $12 \mathrm{~h}$ of exposure of NCI-H446 cells to camptothecin or cisplatin (Fig. 2).

IKK or $\mathrm{NF}-\kappa \mathrm{B}$ activation is ATM phosphorylationdependent in transformed cells (39-41). In the present study, CGK, the ATM inhibitor, not only inhibited the phosphorylation of $\mathrm{I} \kappa \mathrm{B} \alpha$ and $\mathrm{p} 65$ but also blocked p65 translocation from cytoplasm to nucleus (Fig. 5), indicating that ATM phosphorylation is necessary for I $\mathrm{B} \alpha$ phosphorylation in camptothecin or cisplatin-induced $N F-\kappa B$ activation. As IKK $\gamma / \mathrm{NEMO}$ was reported as $\mathrm{NF}-\kappa \mathrm{B}$ essential modulator (39) and PI3K/AKT activation in response to IL-1 stimulation leads to NF- $\kappa \mathrm{B}$ activation (42), both IKK $\gamma / \mathrm{NEMO}$ and PI3K/AKT might induce NF- $\kappa$ B activation. Although ATM phosphorylation was necessary for camptothecin-induced $\mathrm{NF}-\kappa \mathrm{B}$ activation and MDR formation, the mechanisms of phosphorylated ATM inducing $\mathrm{I} \kappa \mathrm{B} \alpha$ phosphorylation by interacting with NEMO or AKT are still unknown and need further investigation.

$\mathrm{NF}-\kappa \mathrm{B}$ is involved in apoptotic response of cells exposed to chemotherapeutic agents (20-23). Activated NF- $\kappa \mathrm{B}$ binds to specific DNA sequences of target genes and regulates gene transcription involved in chemoresistance and radioresistance, including COX-2, cyclin D1, Bcl-2, Bcl-xl, survivin and XIAP (43). In the present study, we have characterized the role of ATM and p65 activation in camptothecin or cisplatin induced ABCG2, MRP2 and Bcl-2 upregulation in NCI-H446 cells (Fig. 5A). Whether other NF- $\kappa$ B components also regulate $\mathrm{ABCG} 2, \mathrm{MRP} 2$ and $\mathrm{Bcl}-2$ expression is still uncertain.

Collectively, our study demonstrated that camptothecin or cisplatin treatment increased expression of ABCG2, MRP2 and Bcl-2 by activating the ATM/NF- $\kappa$ B pathway in human NCI-H446 cells. This study may explain one of the key mechanisms of MDR development following lung cancer chemotherapy. Furthermore, the present research suggests that combined treatment of ATM and NF- $\kappa$ B inhibitors might prevent the development of MDR under clinical conditions.

\section{Acknowledgements}

This study was supported by grants from the National Natural Science Foundation of China (no. 30901738 and 81273203 ), and the Natural Science Foundation of Xiamen (no. 3502Z20104002).

\section{References}

1. Tan XL, Moyer AM, Fridley BL, et al: Genetic variation predicting cisplatin cytotoxicity associated with overall survival in lung cancer patients receiving platinum-based chemotherapy. Clin Cancer Res 17: 5801-5811, 2011.

2. Shinoda C, Maruyama M, Fujishita T, et al: Doxorubicin induces expression of multidrug resistance-associated protein 1 in human small cell lung cancer cell lines by the c-jun N-terminal kinase pathway. Int J Cancer 117: 21-31, 2005.

3. Spiro SG, Tanner NT, Silvestri GA, et al: Lung cancer: progress in diagnosis, staging and therapy. Respirology 15: 44-50, 2010.

4. Yamazaki R, Nishiyama Y, Furuta T, et al: Novel acrylonitrile derivatives, YHO-13177 and YHO-13351, reverse BCRP/ABCG2mediated drug resistance in vitro and in vivo. Mol Cancer Ther 10: 1252-1263, 2011.

5. Kim DH, Sriharsha L, Xu W, et al: Clinical relevance of a pharmacogenetic approach using multiple candidate genes to predict response and resistance to imatinib therapy in chronic myeloid leukemia. Clin Cancer Res 15: 4750-4758, 2009.

6. Doyle LA and Ross DD: Multidrug resistance mediated by the breast cancer resistance protein BCRP (ABCG2). Oncogene 22: 7340-7358, 2003

7. Robey RW, Medina-Pérez WY, Nishiyama K, et al: Overexpression of the ATP-binding cassette half-transporter, ABCG2 (Mxr/BCrp/ABCP1), in flavopiridol-resistant human breast cancer cells. Clin Cancer Res 7: 145-152, 2001.

8. Candeil L, Gourdier I, Peyron D, et al: ABCG2 overexpression in colon cancer cells resistant to SN38 and in irinotecan-treated metastases. Int J Cancer 109: 848-854, 2004.

9. Diestra JE, Scheffer GL, Catala I, et al: Frequent expression of the multi-drug resistance-associated protein BCRP/MXR/ABCP/ ABCG2 in human tumours detected by the BXP-21 monoclonal antibody in paraffin-embedded material. J Pathol 198: 213-219, 2002.

10. Turne JG, Gump JL, Zhang C, et al: ABCG2 expression, function and promoter methylation in human multiple myeloma. Blood 108: 3881-3889, 2006.

11. Yamasaki M, Makino T, Masuzawa T, et al: Role of multidrug resistance protein 2 (MRP2) in chemoresistance and clinical outcome in oesophageal squamous cell carcinoma. Br J Cancer 104: 707-713, 2011.

12. Chen ZS and Tiwari AK: Multidrug resistance proteins (MRPs/ ABCCs) in cancer chemotherapy and genetic diseases. FEBS J 278: 3226-3245, 2011.

13. Spanswick VJ, Lowe HL, Newton C, et al: Evidence for different mechanisms of 'unhooking' for melphalan and cisplatin-induced DNA interstrand cross-links in vitro and in clinical acquired resistant tumour samples. BMC Cancer 12: 436, 2012.

14. Gaudio E, Spizzo R, Paduano F, et al: Tcl1 interacts with ATM and enhances NF- $\mathrm{BB}$ activation in hematologic malignancies. Blood 119: 180-187, 2012.

15. Svirnovski AI, Serhiyenka TF, Kustanovich AM, Khlebko PV, Fedosenko VV, Taras IB and Bakun AV: DNA-PK, ATM and MDR proteins inhibitors in overcoming fludarabine resistance in CLL cells. Exp Oncol 32: 258-262, 2010.

16. Bae JB, Mukhopadhyay SS, Liu L, et al: Snm1B/Apollo mediates replication fork collapse and $S$ Phase checkpoint activation in response to DNA interstrand cross-links. Oncogene 27: 5045-5056, 2008.

17. Bakkenist CJ and Kastan MB: DNA damage activates ATM through intermolecular autophosphorylation and dimer dissociation. Nature 421: 499-506, 2003.

18. Karin M and Greten FR: NF-kappaB: linking inflammation and immunity to cancer development and progression. Nat Rev Immunol 5: 749-759, 2005. 
19. Lin Y, Bai L, Chen $\mathrm{W}$ and Xu S: The NF-kappaB activation pathways, emerging molecular targets for cancer prevention and therapy. Expert Opin Ther Targets 14: 45-55, 2010.

20. Campbell KJ, O'Shea JM and Perkins ND: Differential regulation of NF-kappaB activation and function by topoisomerase II inhibitors. BMC Cancer 6: 101, 2006.

21. Melisi D and Chiao PJ: NF-kappa B as a target for cancer therapy. Expert Opin Ther Targets 11: 133-144, 2007.

22. Konstantinopoulos PA, Fountzilas E, Pillay K, et al: Carboplatininduced gene expression changes in vitro are prognostic of survival in epithelial ovarian cancer. BMC Med Genomics 1: 59 , 2008.

23. Wu ZH, Shi Y, Tibbetts RS and Miyamoto S: Molecular linkage between the kinase ATM and NF-kappaB signaling in response to genotoxic stimuli. Science 311: 1141-1146, 2006.

24. Hu SX, Sui HX, Jin HJ, et al: Lipopolysaccharide and dose of nicotine determine the effects of nicotine on murine bone marrow-derived dendritic cells. Mol Med Rep 5: 1005-1010, 2012.

25. Zhang L, Yu H, Zhao X Lin X, Tan C, Cao G and Wang Z: Neuroprotective effects of salidroside against beta-amyloidinduced oxidative stress in SH-SY5Y human neuroblastoma cells. Neurochem Int 57: 547-555, 2010.

26. Buhrmann C, Mobasheri A, Busch F, Aldinger C, Stahlmann R, Montaseri A and Shakibaei M: Curcumin modulates nuclear factor kappaB (NF-kappaB)-mediated inflammation in human tenocytes in vitro: role of the phosphatidylinositol 3-kinase/Akt pathway. J Biol Chem 286: 28556-28566, 2011.

27. Dioum EM, Osborne JK, Goetsch, S Russell J, Schneider JW and Cobb MH: A small molecule differentiation inducer increases insulin production by pancreatic $\beta$ cells. Proc Natl Acad Sci USA 108: 20713-20718, 2011.

28. Jin HJ, Li HT, Sui HX, Xue MQ, Wang YN, Wang JX and Gao FG: Nicotine stimulated bone marrow-derived dendritic cells could augment HBV specific CTL priming by activating PI3K-Akt pathway. Immunol Lett 146: 40-49, 2012.

29. Heo JI, Oh SJ, Kho, et al: ATM mediates interdependent activation of p53 and ERK through formation of a ternary complex with p-p53 and p-ERK in response to DNA damage. Mol Biol Rep 39: 8007-8014, 2012.

30. Ai L, Skehan RR, Saydi J, Lin T and Brown KD: Ataxiatelangiectasia, mutated (ATM)/nuclear factor $\kappa$ light chain enhancer of activated $\mathrm{B}$ cells $(\mathrm{NF} \kappa \mathrm{B})$ signaling controls basal and DNA damage-induced transglutaminase 2 expression. J Biol Chem 287: 18330-18341, 2012.
31. Togashi H, Sasaki M, Frohman E, et al: Neuronal (type I) nitric oxide synthase regulates nuclear factor $\kappa \mathrm{B}$ activity and immunologic (type II) nitric oxide synthase expression. Proc Natl Acad Sci USA 94: 2676-2680, 1997.

32. Tenopoulou M, Kurz T, Doulias PT, Galaris D and Brunk UT: Does the calcein-AM method assay the total cellular 'labile iron pool' or only a fraction of it? Biochem J 403: 261-266, 2007.

33. Zolner AE, Abdou I, Ye R, et al: Phosphorylation of polynucleotide kinase/ phosphatase by DNA-dependent protein kinase and ataxia-telangiectasia mutated regulates its association with sites of DNA damage. Nucleic Acids Res 39: 9224-9237, 2011.

34. Alexande A, Cai SL, Kim J, et al: ATM signals to TSC2 in the cytoplasm to regulate mTORC1 in response to ROS. Proc Natl Acad Sci USA 107: 4153-4158, 2010.

35. Korita PV, Wakai T, Shirai Y, et al: Multidrug resistance associated protein 2 determines the efficacy of cisplatin in patients with hepatocellular carcinoma. Oncol Rep 23: 965-972, 2010.

36. Yasui K, Mihara S, Zhao C, et al: Alteration in copy numbers of genes as a mechanism for acquired drug resistance. Cancer Res 64: 1403-1410, 2004

37. Cho S, Lu M, He X, Ee PL, Bhat U, Schneider E, Miele L and Beck WT: Notch1 regulates the expression of the multidrug resistance gene $A B C C 1 / M R P 1$ in cultured cancer cells. Proc Natl Acad Sci USA 108: 20778-20783, 2011.

38. Bram EE, Stark M, Raz S and Assaraf YG: Chemotherapeutic drug-induced ABCG2 promoter demethylation as a novel mechanism of acquired multidrug resistance. Neoplasia 11: 1359-1370, 2009

39. Yang Y, Xia F, Hermance N, et al: A cytosolic ATM/NEMO/ RIP1 complex recruits TAK1 to mediate the NF-kappaB and p38 mitogen-activated protein kinase (MAPK)/MAPK-activated protein 2 responses to DNA damage. Mol Cell Biol 31: 2774-2786, 2011.

40. Miyamoto S: Nuclear initiated NF- $\kappa B$ signaling: NEMO and ATM take center stage. Cell Res 21: 116-130, 2011.

41. Wu ZH and Miyamoto S: Induction of a pro-apoptotic ATM-NF- $\kappa B$ pathway and its repression by ATR in response to replication stress. EMBO J 27: 1963-1973, 2008.

42. Ling J, Kang Y, Zhao R, et al: $\mathrm{Kras}^{\mathrm{G} 12 \mathrm{D}}$-induced IKK2/ $\beta / \mathrm{NF}-\varkappa \mathrm{B}$ activation by IL- $1 \alpha$ and p62 feedforward loops is required for development of pancreatic ductal adenocarcinoma. Cancer Cell 21: 105-120, 2012.

43. Li F and Sethi G: Targeting transcription factor NF- $\kappa$ B to overcome chemoresistance and radioresistance in cancer therapy. Biochim Biophys Acta 1805: 167-180, 2010. 